
\title{
$\angle S$ Research Square \\ Unimproved water, sanitation, and hygiene (WASH) and common childhood illness in Myanmar: evidence from a nationally representative survey
}

\section{Lubna Naz}

University of Karachi

Umesh Ghimire ( $\nabla$ creationumesh@gmail.com )

New ERA https://orcid.org/0000-0002-4246-8379

\section{Research article}

Keywords: Common childhood illness, Under-five children, Diarrhea, WASH, Myanmar

Posted Date: June 18th, 2020

DOI: https://doi.org/10.21203/rs.3.rs-36037/v1

License: (c) (i) This work is licensed under a Creative Commons Attribution 4.0 International License. Read Full License 


\section{Abstract \\ Background}

Inadequate Water, Hygiene and Sanitation (WASH) is one of the major risk factors of common childhood illness - namely, diarrhea, cough, fever, and acute respiratory infection, in many Southeast Asian countries. This study aims to analyze the relationship between WASH-related indicators and common childhood illnesses; cough, fever and diarrhea among underfive children in Myanmar.

\section{Methods}

The data of 4,815 under-fives was extracted from the first Myanmar Demographic and Health Survey 2015-16. Chisquare test was used to determine association between WASH and sociodemographic variables and each common childhood illness. The bivariate logistic regression was used to obtain the unadjusted odds of cough, fever, and diarrhea for each wash indicator, i.e., Unimproved toilet, access to unsafe water, and unsafe feces disposal. Further multivariate regression was employed and adjusted odd ratios were obtained of each common childhood illness after accounting for all wash indicators.

\section{Results}

Among under-five children, $16.2 \%$ suffered from cough, $16 \%$ suffered from fever, and $10.4 \%$ from diarrhea. Unimproved toilet facility was associated with cough (Adjusted Odds Ratio (AOR) 1.15, 95\% Cl:0.86, 1.22), and fever (AOR 1.03, 95\% $\mathrm{Cl}: 0.86,1.23)$ among children. Children from households practicing unimproved child feces disposal had $21 \%, 18 \%$, and $52 \%$ higher odds of experiencing cough (95\% Cl:1.12, 1.31), fever (95\% Cl: 0.99,1.29), and diarrhea (95\% Cl:1.21, 1.68), respectively. A combination of unimproved water, toilet and child feces disposal facilities was associated with cough (AOR 1.34, 95\% Cl:1.03, 1.73), fever (AOR 1.12, 95\% Cl:0.86, 1.19) and diarrhea (AOR 1.18, 95\% Cl:0.95, 1.29).

\section{Conclusion}

Inadequate improved WASH significantly contributed to common childhood illnesses among children in Myanmar. Findings suggest that WASH interventions should be targeted to the poor and rural areas where the prevalence of both childhood illnesses and unimproved WASH facilities were reportedly high.

\section{Background}

Globally, 2.2 billion (29\%) people did not have access to protected potable water, and 4.2 billion (55\%) still lacked access to toilet facility or safe disposal of child excreta in 2017 [1]. Around 128,500 deaths of under-five children occurred due to unprotected drinking water, unavailability of basic sanitation, and unhygienic in the world [2]. Inadequate water, sanitation and hygiene (WASH) is one of the major risk factors of the common childhood illness; namely diarrhea, cough, fever, and acute respiratory infection (ARI) in many Southeast Asian and Sub-Saharan countries [3-5]. WASH alone contributes to $7 \%$ of overall disease burden in the least developing countries [6]. Most of diarrhea-related morbidities can be averted by ensuring access to protected water and clean environment [7]. The provision of basic sanitation and hygiene can avert 2.4 million deaths each year [8]. The "Goal 6 of Sustainable Development Goals (SDGs) calls for to ensure availability and sustainable management of water and sanitation for all, and particularly targets 6.1 and 6.2 are related to achieving the universal access to safe and affordable drinking water, and providing equitable and adequate sanitation, and hygiene, respectively" [9]. 
Myanmar in still going through a recovery period after the prolonged civil unrest that had dismantled the country's social, political, and economic development [10]. According to the 2018 Human Development Index, Myanmar was positioned at 148 ranks out of 189 countries [11]. Inequality in health service delivery exists in the country due to several socioeconomic and geographic disparities [12]. The majority of the population (70\%) in the country lives in rural areas. The rural households are deprived of necessary civic facilities due to frequent occurrence of conflicts, rampant poverty, lack of community participation, and inadequate knowledge of managing natural resources $[12,13]$.

Moreover, the country has long been facing with problems of unsafe potable water and inadequate sanitation; $11 \%$ people in the urban and one-third of population (34\%) in rural do not have access to the protected water supply. Only three-fourth (76\%) has adequate sanitation facilities [14]. Diarrhea is the fourth primary cause of childhood fatality, making up $7.7 \%$ of the total under-five deaths in Myanmar [15].

The universal access to safe potable water and improved sanitation are recognized as fundamental human rights worldwide, as endorsed by the "General Assembly of the United Nations" [16]. Like many other countries, Myanmar has committed to meet the targets of SDG-6 by 2030 . For that, the country needs to ensure the equitable and universal accessibility of adequate WASH to all people. The literature suggests that household-related environmental factors constrain childhood development and diminish the prospects of school attainment and a decent livelihood in less developing countries [2, 17-22]. The Myanmar Demographic and Health survey 2015-16 is the first household survey conducted in Myanmar. It provides extensive information on the environmental factors relating to household, such as "water, sanitation and hygiene". The information can be used to assess the impact of WASH on preventable diseases among preschool children.

This study makes the first attempt to explore the prevalence of common childhood illnesses in respect to householdrelated environmental factors, water, sanitation and hygiene - WASH in Myanmar by using the first MDHS 2015-16. The findings may help devise multipronged health care strategies to address inadequate WASH and decrease the burden of common childhood diseases in Myanmar.

\section{Material And Methods}

\section{Data and sample selection}

This study used a sample of 4,815 under-five children from the Myanmar Demographic and Health Survey (MDHS 201516). MDHS used a two-stage stratified clustered sampling framework. The sampling design contained 76,990 primary sampling units (PSUs). Out of 30 sampling strata and 441 clusters, a selection of 30 households was made by using probability proportional to size rule (PPS). A total of 12,885 women aged 15 to 49 years were interviewed from 13,230 households, and data was compiled in women's file (KR), yielding a response rate of $98 \%$. The information on sociodemographic factors, maternal and children's health, fertility, reproductive health, family planning, pregnancy, postnatal care, and immunization were collected using the Standard DHS tools. MDHS can be accessed freely from the publicly available data repository via the "DHS Program" website (https://www.dhsprogram.com/data/).

\section{Data Processing}

Ethical Review Committee of the Myanmar Ministry of Health and Sports, Department of Medical Research granted ethical approval for the implementation of MDHS [23]. The data collection held from December 7, 2015, through July 7 2016, by 19 trained field teams. The field editors used computer-assisted field editing (CAFE) procedures to enter the completed paper questionnaires soon after data collection. Completed questionnaires were entered twice to check for the inconsistencies using CSPro software. 


\section{Outcome variable}

We examined three childhood illnesses; cough, fever, and diarrhea as dependent variables. MDHS enquired women aged 15-49 whether their children had diarrhea and/or fever, and/or cough in the past two weeks preceding the survey. The answers were recorded as 'Yes' or 'No'. The definition of diarrhea was read to the mothers to ensure that the mothers understood diarrhea and validate the accuracy of responses. This paper used the information on cough, fever, and diarrhea as reported by mothers to form dichotomous (0/1) outcome variables; where 1 implies the under-five child suffered by the disease, and 0 means not-experienced.

\section{Explanatory variables}

We used three WASH-related variables as explanatory variables: water, sanitation (toilet facility), and child feces disposal by households. The standard guidelines for the grouping of improved and unimproved sanitation, "as recommended by the WHO/UNICEF Joint Monitoring Program (JMP) for Water Supply and Sanitation, were used (Table 1) [24]”.

Table 1 WHO classification of improved sanitation and water supply

\begin{tabular}{|c|c|c|}
\hline & Unimproved & Improved \\
\hline Water & $\begin{array}{l}\text { Unimproved-drinking-water sources: Unprotected dug } \\
\text { well, unprotected spring, cart with small tank/drum, } \\
\text { surface water (river, dam, lake, pond, stream, canal, } \\
\text { irrigation channels), and bottled water }\end{array}$ & $\begin{array}{l}\text { Other improved drinking-water sources: Public taps or standpipes, tube } \\
\text { wells or boreholes, protected dug wells, protected springs or rainwater } \\
\text { collection. Piped water on premises: Piped household water connection } \\
\text { located inside the user's dwelling, plot or yard }\end{array}$ \\
\hline $\begin{array}{l}\text { Sanitation } \\
\text { and child's } \\
\text { excreta } \\
\text { disposal } \\
\text { facilities }\end{array}$ & $\begin{array}{l}\text { Unimproved sanitation facilities: do not ensure hygienic } \\
\text { separation of human excreta from human contact. } \\
\text { Unimproved facilities include pit latrines without a slab } \\
\text { or platform, hanging latrines and bucket latrines. }\end{array}$ & $\begin{array}{l}\text { Improved sanitation facilities: ensure hygienic separation of human } \\
\text { excreta from human contact. They are use of the following facilities: } \\
\text { Flush/pour flush to: piped sewer system, septic tank, pit latrine; Ventilated } \\
\text { improved pit (VIP) latrine, Pit latrine with slab, Composting toilet. }\end{array}$ \\
\hline
\end{tabular}

Source: WHO/UNICEF Joint Monitoring Programme for Water Supply and Sanitation.

Households' access to different water sources was regrouped into safe drinking water or unsafe water. The responses of households interviewed about the type of toilet were combined into two responses; unimproved latrine, and improved latrine. Similarly, the practices of child feces disposal were organized into two categories, as follows, safe disposal of child feces and unsafe disposal. The binary variable (0/1) was used to represent each WASH-related indicator, 1 implies unimproved, and 0 means improved.

Other independent variables included child characteristics, such as child sex (categorical: male or female); age in months (categorical: 1-12, 13-24, 25-36, 37-48 and 49-59); child birth size (categorical: very small, average or smaller but not very small, and above average or very large); and nutritional status (binary: stunting, wasting, and underweight). The parent characteristics used in this study included mother's age in years (categorical: less than 20, 20-29, 30-39, and 40-49); mother's education (categorical: no education, primary, secondary or higher), and father's education (categorized as mother's education). The household-related variables comprised type of residence (categorical: urban or rural), and children in the households (categorical: 1-2, 3-4, and more than 4).

MDHS 2015-16 collected detailed information on durable assets and housing features. It used Principle Component Analysis (PCA) to derive the factor scores of household wealth based on the obtained data. The Household wealth in the MDHS was categorized in terms five quintiles: "poorest, poorer, middle, richer, and richest". We re-organized the wealth 
index by combining first three wealth quintiles "(poorest, poorer, and middle)" into "poor" and last two quintiles "(richer and richest)" into rich.

\section{Data Analysis}

Cross-tabulation between socio-demographic characteristics and WASH-related indicators were presented as frequency distribution and in percentage. Since this study involved mostly categorical variables, we employed Pearson Chi-square test to determine the relationship between each explanatory variable and dependent variable. Three levels of significance, " $p<0.001, p<0.05, p<0.01$ ", were used.

This study analyzed the prevalence of each cough, fever, and diarrhea across childhood characteristics, parent-related, and household-related factors. The univariate and bivariate statistical analyses were employed over a weighted sample. The bivariate relationships between each explanatory variable and each childhood illness were appraised at a $95 \%$ confidence interval. A p-value $<0.05$ indicates a statistically significant relationship. The multivariate logistic regression was used to assess the association between WASH indicators and each childhood disease; diarrhea, fever, and cough. The unadjusted odd ratios (reference category=use of adequate WASH) showed the odds of cough, fever and diarrhea for unsafe drinking water, unimproved toilet, and hazardous child feces disposal separately. The adjusted odds ratios showed the likelihood of diarrhea, cough, and fever for each WASH indicator while controlling for other indicators. Sampling weights were used while estimating the logistic model to adjust for the sampling errors and complex sampling design. The analysis was performed in Stata, version 15.

\section{Results}

Among under-five children included in the study, $52.5 \%$ were male. One-third (33\%) of households had access to unprotected potable water, and $47 \%$ had an unimproved toilet. The same proportion of families opted for unsafe child feces disposal. The households with almost $40 \%$ of children aged 1-24 months reported a higher prevalence of unimproved child feces disposal. Nearly three fourth (73.3\%) children in the study had a higher than average or average birth size, and birth size varied significantly across various indicators of WASH.

The rate of stunting was higher in households with unimproved toilet facility (33.6\%), and unsafe feces disposal (30.7\%), and $7.9 \%$ of wasted children were from the families having access to unprotected water. The prevalence of underweight was higher in households with unimproved toilet facility (20.9\%), and unsafe feces disposal (19.4\%). The majority of women (43.2\%) were between the age-group 20-29 years, and $17 \%$ of mothers and fathers were illiterate. More than three fourth $(78.9 \%)$ of respondents were from rural areas, and $71.3 \%$ belonged to the poor economic background. $14 \%$ of households had more than four children (Table 2). 
Table 2

Background characteristics of under-five children according to the WASH indicators

\begin{tabular}{|c|c|c|c|c|}
\hline \multirow{3}{*}{ Variables } & \multirow{3}{*}{$\begin{array}{l}\text { Total } \\
\mathrm{N}=4,815\end{array}$} & \multicolumn{3}{|c|}{$\begin{array}{l}\text { Unimproved water, toilet and child feces disposal facilities in } \\
\text { households }\end{array}$} \\
\hline & & $\begin{array}{l}\text { Unimproved } \\
\text { Water }\end{array}$ & $\begin{array}{l}\text { Unimproved } \\
\text { Toilet }\end{array}$ & $\begin{array}{l}\text { Unimproved Child feces } \\
\text { disposal }\end{array}$ \\
\hline & & $32.97 \%$ & $47.63 \%$ & $46.63 \%$ \\
\hline & $\mathrm{N} / \%$ & $\%$ & $\%$ & $\%$ \\
\hline \multicolumn{5}{|l|}{ Child sex } \\
\hline Male & $2528 / 52.50$ & 51.33 & 52.54 & 53.59 \\
\hline Female & $2267 / 47.50$ & 48.67 & 47.46 & 46.41 \\
\hline p-value & & 0.25 & 0.95 & 0.130 \\
\hline \multicolumn{5}{|l|}{ Child age } \\
\hline $1-12$ & $1049 / 21.79$ & 22.22 & 21.49 & 30.73 \\
\hline $13-24$ & $966 / 20.06$ & 21.21 & 19.53 & 21.71 \\
\hline $25-36$ & $852 / 17.69$ & 18.37 & 17.95 & 16.74 \\
\hline $37-48$ & $1100 / 22.85$ & 23.04 & 22.72 & 17.62 \\
\hline $49-59$ & $848 / 17.61$ & 15.15 & 18.35 & 13.20 \\
\hline p-value & & 0.03 & 0.72 & 0.000 \\
\hline \multicolumn{5}{|l|}{ Birth size } \\
\hline Very small & $69 / 1.49$ & 2.02 & 1.80 & 2.17 \\
\hline Larger than average/average & $3443 / 73.35$ & 76.66 & 73.82 & 71.57 \\
\hline $\begin{array}{l}\text { Greater than average/very } \\
\text { large }\end{array}$ & $1119 / 24.16$ & 21.33 & 24.38 & 26.25 \\
\hline p-value & & 0.001 & 0.129 & 0.000 \\
\hline \multicolumn{5}{|l|}{ Stunted } \\
\hline No & $2927 / 69.48$ & 70.99 & 66.33 & 69.26 \\
\hline Yes & $1286 / 30.52$ & 29.01 & 33.67 & 30.74 \\
\hline p-value & & 0.133 & 0.00 & 0.01 \\
\hline \multicolumn{5}{|l|}{ Wasting } \\
\hline No & $3917 / 93.33$ & 92.09 & 92.80 & 93.09 \\
\hline Yes & $280 / 6.67$ & 7.91 & 7.20 & 6.91 \\
\hline $\mathrm{p}$-value & & 0.02 & 0.174 & 0.46 \\
\hline \multicolumn{5}{|l|}{ Underweight } \\
\hline No & $3429 / 81.31$ & 81.44 & 78.03 & 80.55 \\
\hline
\end{tabular}




\begin{tabular}{|c|c|c|c|c|}
\hline \multirow[b]{2}{*}{ Yes } & \multirow[b]{2}{*}{ 788/18.69 } & \multicolumn{3}{|c|}{$\begin{array}{l}\text { Unimproved water, toilet and child feces disposal facilities in } \\
\text { households }\end{array}$} \\
\hline & & 18.56 & 20.97 & 19.45 \\
\hline p-value & & 0.85 & 0.000 & 0.01 \\
\hline \multicolumn{5}{|l|}{ Mother education } \\
\hline No education & $860 / 17.86$ & 19.76 & 24.17 & 21.76 \\
\hline Primary & $2132 / 44.28$ & 38.19 & 50.44 & 46.69 \\
\hline Secondary or higher & $1823 / 37.86$ & 42.05 & 25.39 & 31.55 \\
\hline$p$-value & & 0.000 & 0.000 & 0.000 \\
\hline \multicolumn{5}{|l|}{ Mother's age } \\
\hline Less than 20 years & $104 / 2.16$ & 1.96 & 2.36 & 2.76 \\
\hline $20-29$ & 2081/43.22 & 44.0 & 44.75 & 47.88 \\
\hline $30-39$ & $2059 / 42.76$ & 43.94 & 42.08 & 38.68 \\
\hline $40-49$ & $571 / 11.86$ & 10.10 & 10.81 & 10.67 \\
\hline p-value & & 0.04 & 0.06 & 0.000 \\
\hline \multicolumn{5}{|l|}{ Father education } \\
\hline No education & $839 / 17.43$ & 17.19 & 23.51 & 21.85 \\
\hline Primary & $1890 / 39.27$ & 34.70 & 44.35 & 41.86 \\
\hline Secondary or higher & 2084/43.30 & 48.10 & 32.14 & 36.29 \\
\hline$p$-value & & 0.000 & 0.000 & 0.000 \\
\hline \multicolumn{5}{|l|}{ Type of residence } \\
\hline Rural & $3803 / 78.98$ & 68.50 & 89.32 & 86.71 \\
\hline Urban & 1012/21.02 & 31.50 & 10.68 & 13.29 \\
\hline p-value & & 0.000 & 0.000 & 0.000 \\
\hline \multicolumn{5}{|l|}{ Socioeconomic status } \\
\hline Poor & $3434 / 71.32$ & 977 & 88.27 & 79.85 \\
\hline Rich & $1381 / 28.68$ & 38.32 & 11.73 & 20.15 \\
\hline p-value & & 0.00 & 0.000 & 0.000 \\
\hline \multicolumn{5}{|c|}{ Number of children in household } \\
\hline $1-2$ & $2641 / 55.23$ & 59.94 & 50.86 & 51.61 \\
\hline $3-4$ & $1470 / 30.74$ & 29.55 & 32.67 & 32.61 \\
\hline$>4$ & $671 / 14.03$ & 10.51 & 16.47 & 15.38 \\
\hline$p$-value & & 0.000 & 0.000 & 0.000 \\
\hline$\star \star p<0.05 ; * \star \star p<<0.00$ & & & & \\
\hline
\end{tabular}


In Myanmar, a higher percentage of preschool children (16.2\%. 95\% Cl: 14.9, 17.5) suffered from cough, followed by fever (16.0\%, 95\% Cl: 14.83, 17.39), and diarrhea (10.4\%, 95\% Cl: 9.4, 11.5), in two weeks before the survey. The prevalence of childhood illnesses was high among males, and children below two years of age. Nearly one-third (31.1\% 95\% Cl: 26.1, $36.6)$ of stunted children and more than one fifth $(22.0 \%, 95 \% \mathrm{Cl}: 17.6,27.1)$ of underweight children had diarrhea. Likewise, $29.8 \%$ (95\% Cl: 25.9, 34.0) of stunted children had a cough. Of three childhood illnesses, diarrhea among underfive children showed association (statistically significant) to the age of mother, mother's education, rural/urban, and household socioeconomic status. Similarly, childhood experience of cough was significantly related to the mother's age. The socioeconomic status of households showed statistically significant association with fever (Table 3 ). 
Table 3

The prevalence of Cough, Fever, and Diarrhea among under-five children in Myanmar (weighted sample)

\begin{tabular}{|c|c|c|c|}
\hline Variables & Cough & Fever & Diarrhea \\
\hline & $16.23[14.9-17.5]$ & $16.07[14.83-17.39]$ & $10.45[9.4-11.5]$ \\
\hline Male & $54.5[49.8-58.2]$ & $50.2[45.8-54.5]$ & $52.5[47.1-57.9]$ \\
\hline Female & $45.9[41.7-50.1]$ & $49.7[45.4-54.1]$ & $47.4[42.0-52.8]$ \\
\hline p-value & 0.12 & 0.64 & 0.41 \\
\hline \multicolumn{4}{|l|}{ Child age } \\
\hline $0-12$ & $19.23[16.2-22.6]$ & $22.01[18.6-25.7]$ & $20.3[16.4-24.9]$ \\
\hline $13-24$ & $26.2[22.6-30.2]$ & $28.3[24.5-32.3]$ & $38.11[32.9-43.5]$ \\
\hline $25-36$ & $18.8[15.7-22.3]$ & $18.5[15.3-22.2]$ & $15.5[12.0-19.7]$ \\
\hline $37-48$ & $20.5[17.3-24.2]$ & $18.6[15.5-22.3]$ & $16.3[12.8-20.6]$ \\
\hline $49-59$ & $15.0[12.2-18.3]$ & $12.4[9.8-15.4]$ & $9.6[6.8-13.4]$ \\
\hline p-value & 0.000 & 0.000 & 0.000 \\
\hline \multicolumn{4}{|l|}{ Birth size } \\
\hline Very small & $2.3[1.3-3.9]$ & $2.2[1.2-4.1]$ & $1.9[0.8-4.2]$ \\
\hline Larger than average/average & $71.2[67.2-74.9]$ & $68.5[64.3-72.5]$ & $69.1[63.7-73.9]$ \\
\hline Greater than average/very large & $26.4[22.8-30.3]$ & $29.1[25.2-33.2]$ & $28.9[24.2-34.2]$ \\
\hline p-value & 0.02 & 0.00 & 0.001 \\
\hline \multicolumn{4}{|l|}{ Stunted } \\
\hline No & $70.1[65.90-74.0]$ & $70.8[66.5-74.8]$ & $68.8[63.3-73.8]$ \\
\hline Yes & $29.8[25.9-34.0]$ & $29.1[25.1-33.4]$ & $31.1[26.1-36.6]$ \\
\hline p-value & 0.02 & 0.05 & 0.001 \\
\hline \multicolumn{4}{|l|}{ Wasting } \\
\hline No & $92.6[90.6-94.6]$ & $91.7[88.9-93.9]$ & $91.0[87.1-93.7]$ \\
\hline Yes & $7.3[5.3-9.9]$ & $8.2[6.7-11.0]$ & $8.9[6.2-12.8]$ \\
\hline p-value & 0.50 & 0.35 & 0.25 \\
\hline \multicolumn{4}{|l|}{ Underweight } \\
\hline No & $78.9[75.0-82.4]$ & $78.5[74.4-82.0]$ & $77.9[72.8-82.3]$ \\
\hline Yes & $21.0[17.5-24.9]$ & $21.4[17.9-25.5]$ & $22.0[17.6-27.1]$ \\
\hline$p$-value & 0.74 & 0.97 & 0.00 \\
\hline
\end{tabular}

${ }^{\star *} \mathrm{p}<0.05 ;{ }^{* \star *} \mathrm{p}<0.001,{ }^{\star} \mathrm{p}<0.01$ 


\begin{tabular}{|c|c|c|c|}
\hline Variables & Cough & Fever & Diarrhea \\
\hline No education & $15.9[13.1-19.1]$ & $17.3[14.3-20.8]$ & $18.19[14.4-22.6]$ \\
\hline Primary & $46.8[42.6-51.1]$ & $47.7[43.4-52.0]$ & $46.1[40.7-51.5]$ \\
\hline Secondary or higher & $37.2[33.2-41.4]$ & $34.8[30.8-39.1]$ & $35.6[30.6-41.0]$ \\
\hline$p$-value & 0.48 & 0.85 & 0.03 \\
\hline \multicolumn{4}{|l|}{ Mother's age } \\
\hline Less than 20 years & $2.4[1.4-4.7]$ & $2.6[1.5-4.3]$ & $1.8[0.08-3.8]$ \\
\hline $20-29$ & $43.2[39.1-47.5]$ & $45.5[41.3-49.9]$ & 48.3[43.0-53.7] \\
\hline $30-39$ & $44.8[40.6-49.0]$ & $41.9[37.7-46.2]$ & $42.1[36.9-47.5]$ \\
\hline $40-49$ & $9.4[7.3-12.9]$ & $9.8[7.5-12.6]$ & $7.6[5.2-10.9]$ \\
\hline p-value & 0.04 & 0.82 & 0.02 \\
\hline \multicolumn{4}{|l|}{ Father's education } \\
\hline No education & $12.8[10.3-15.7]$ & 15.5[12.7-18.8] & $16.6[13.0-20.9]$ \\
\hline Primary & $41.7[37.5-45.9]$ & $45.6[41.3-49.9]$ & $41.8[36.6-47.3]$ \\
\hline Secondary or higher & $45.4[41.2-49.6]$ & $38.8[34.7-43.1]$ & $41.4[36.2-46.8]$ \\
\hline p-value & 0.012 & 0.16 & 0.71 \\
\hline \multicolumn{4}{|l|}{ Type of residence } \\
\hline Rural & $73.6[22.6-30.3]$ & $76.9[19.5-27.0]$ & $81.9[77.3-85.6]$ \\
\hline Urban & $26.3[22.6-30.3]$ & 23.0[19.5-27.0] & $18.0[14.3-22.6]$ \\
\hline p-value & 0.78 & 0.32 & 0.003 \\
\hline \multicolumn{4}{|l|}{ Socioeconomic status } \\
\hline Poor & $69.1[64.9-72.9]$ & $73.4[69.4-77.1]$ & $77.0[72.1-81.3]$ \\
\hline Rich & $30.8[27.0-35.0]$ & $26.5[22.8-30.5]$ & $22.9[18.6-27.8]$ \\
\hline $\mathrm{p}$-value & 0.05 & 0.02 & 0.00 \\
\hline \multicolumn{4}{|l|}{ Number of children } \\
\hline $1-2$ & $59.9[55.7-64.0]$ & $61.5[57.4-65.7]$ & $64.5[59.3-69.4]$ \\
\hline $3-4$ & 29.6-25.9-33.7] & $28.4[24.7-32.5]$ & $25.3[21.0-30.1]$ \\
\hline$>4$ & $10.3[8.2-12.8]$ & $9.8[7.7-12.3]$ & $10.0[7.4-13.5]$ \\
\hline$p$-value & 0.15 & 0.15 & 0.14 \\
\hline
\end{tabular}

The childhood illnesses; cough, fever, diarrhea, were higher among households with unimproved toilet facility (Fig. 1). However, the disparity was not observed in the case of the occurrence of cough, fever, and diarrhea in children by 
improved or unimproved water facilities at the household (Fig. 2). The rate of childhood illness was higher among households reporting unimproved child feces disposal facilities (Fig. 3).

The multivariate analysis showed that children of households which did not have improved toilet facility were associated with cough “(Adjusted Odds Ratio [AOR] 1.15, 95\% Cl:0.86, 1.22) and fever (AOR 1.03, 95\% Cl:0.86, 1.23)" (Table 4).

Table 4

The adjusted and unadjusted odd ratios of Cough, Fever, and Diarrhea

\begin{tabular}{|c|c|c|c|c|c|c|}
\hline \multirow[t]{2}{*}{ Variables } & \multicolumn{2}{|l|}{ Cough } & \multicolumn{2}{|l|}{ Fever } & \multicolumn{2}{|l|}{ Diarrhea } \\
\hline & $\begin{array}{l}\text { Unadjusted } \\
\text { OR [95\% Cl] }\end{array}$ & $\begin{array}{l}\text { Adjusted } \\
\text { OR [95\% } \\
\text { CI] }\end{array}$ & $\begin{array}{l}\text { Unadjusted } \\
\text { OR [95\% Cl] }\end{array}$ & $\begin{array}{l}\text { Adjusted } \\
\text { OR [95\% } \\
\text { Cl] }\end{array}$ & $\begin{array}{l}\text { Unadjusted } \\
\text { OR }[95 \% \mathrm{Cl}]\end{array}$ & $\begin{array}{l}\text { Adjusted } \\
\text { OR [95\% Cl] }\end{array}$ \\
\hline \multicolumn{7}{|c|}{ Water facility (UIM) } \\
\hline No & 1 & 1 & 1 & 1 & 1 & 1 \\
\hline Yes & $\begin{array}{l}0.96[0.82- \\
1.12]\end{array}$ & $\begin{array}{l}1.06[0.89- \\
1.26]\end{array}$ & $\begin{array}{l}1.10[0.94- \\
1.24]\end{array}$ & $\begin{array}{l}0.94[0.79- \\
1.13]\end{array}$ & $\begin{array}{l}0.86[0.71- \\
1.04]\end{array}$ & $\begin{array}{l}0.93[0.75- \\
1.16]\end{array}$ \\
\hline \multicolumn{7}{|c|}{ Toilet facility (UIM) } \\
\hline No & 1 & 1 & 1 & 1 & 1 & 1 \\
\hline Yes & $\begin{array}{l}0.93[0.80- \\
1.07]\end{array}$ & $\begin{array}{l}1.15^{\star} \\
{[0.86-} \\
1.22]\end{array}$ & $\begin{array}{l}1.00[0.86- \\
1.17]\end{array}$ & $\begin{array}{l}1.03^{*} \\
{[0.86-} \\
1.13]\end{array}$ & $\begin{array}{l}0.91[0.81- \\
1.15]\end{array}$ & $\begin{array}{l}0.96[0.78- \\
1.12]\end{array}$ \\
\hline \multicolumn{7}{|c|}{$\begin{array}{l}\text { Child feces disposal } \\
\text { (UIM) }\end{array}$} \\
\hline No & 1 & 1 & 1 & 1 & 1 & 1 \\
\hline Yes & $\begin{array}{l}1.08[0.94- \\
1.25]\end{array}$ & $\begin{array}{l}1.21 \text { ** } \\
{[1.12-} \\
1.31]\end{array}$ & $\begin{array}{l}1.15^{\star \star}[0.91- \\
1.65]\end{array}$ & $\begin{array}{l}1.18^{* *} \\
{[0.99-} \\
1.29]\end{array}$ & $\begin{array}{l}1.40 \star \star \star \\
{[1.76-1.58]}\end{array}$ & $\begin{array}{l}1.52^{\star \star \star} \\
{[1.21-1.68]}\end{array}$ \\
\hline \multicolumn{7}{|c|}{$\begin{array}{l}\text { Water + Toilet + child } \\
\text { feces disposal (UIM) }\end{array}$} \\
\hline No & 1 & 1 & 1 & 1 & 1 & 1 \\
\hline Yes & $\begin{array}{l}1.15^{\star}[0.97- \\
1.37]^{[}\end{array}$ & $\begin{array}{l}1.34^{\star *} \\
{[1.03-} \\
1.73]\end{array}$ & $\begin{array}{l}1.01[0.84- \\
1.21]\end{array}$ & $\begin{array}{l}1.12^{\star \star} \\
{[0.86-} \\
1.19]\end{array}$ & $\begin{array}{l}0.94[0.75- \\
1.18]\end{array}$ & $\begin{array}{l}1.18^{\star} \\
{[0.95-1.29]}\end{array}$ \\
\hline
\end{tabular}

Children of mothers who opted for unimproved child feces disposal had $21 \%, 18 \%$, and $52 \%$ higher odds of suffering from cough (AOR 1.21, 95\% Cl: 1.02, 1.44), fever (AOR 1.18, 95\% Cl: 0.99,1.89), and diarrhea (AOR 1.52, 95\% Cl: 1.21, 1.90), respectively, compared to children of mother who didnot. A combination of unimproved water, toilet, and child feces disposal facilities were positively associated with cough (AOR 1.34, 95\% Cl: 1.03, 1.73), fever (AOR 1.12, 95\% Cl: $0.86,1.59)$ and diarrhea (AOR $1.18,95 \% \mathrm{Cl}: 0.85,1.69)$. However, we did not find statistically significant association in the case of unimproved water facility and any of the childhood illnesses. 


\section{Discussion}

This study used the first DHS from Myanmar to assess the association between three common childhood illnesses and indicators of WASH. It also examined the prevalence of childhood illnesses across various sociodemographic characteristics of children, their parents, and households. The descriptive analysis suggested that a higher proportion of households did not have access to improved water and toilet facilities in Myanmar. The cough was the most prevalent amongst all three childhood illnesses under study, followed by fever and diarrhea. The unimproved toilet facility was significantly associated with childhood cough and fever in Myanmar.

Similarly, children from those households practicing unimproved child feces disposal were associated with higher risks (odds) of suffering from cough, fever, and diarrhea. The odds of childhood illnesses (cough, fever, and diarrhea) increased significantly if the combination of unimproved water, toilet, and child feces disposal practices were present in the same household. The unimproved WASH practices were common in rural areas and among the poor. Children of the younger and uneducated mother were more associated inadequate WASH.

According to the World Health Organization report, three-fourth or $77 \%$ has access to improved sanitation. A higher number of urban inhabitants use improved water source and sanitation facilities compared to their rural counterparts [10]. Several ministries under the government in coordination with international institutions are working to improve sanitation and drinking-water services in Myanmar. Most of the non-governmental orgainzations (NGOs) are based in cities that have abetted in building WASH infrastructures in urban neighborhoods. Nevertheless, Myanmar has made some progress in recent years to expand the coverage of improved WASH; it is still struggling to provide necessary water, sanitation, and hygiene services, especially in rural areas [25].

The one-third ( 2.5 billion) of the global population do not have adequate sanitation facility, and $70 \%$ of that belong to rural [24]. Rural areas have several WASH-related problems including open defecation and limited access to safe potable water. Around $9 \%$ of the population in Myanmar are still involved in the open defecation [24]. One of the potential barriers to embracing safe hygiene practices in rural areas is poverty [26]. Latrines, mostly in the rural regions of LMICs are poorly built and emit noxious odors, and chances are higher that children could be bitten by insects or rats [27]. According to the study based on behavioral intervention from rural India, nearly half of newly-constructed toilets were dysfunctional or unused [28]. Open excretion, particualrly in rural areas, in many less developing countries is socially acceptable, and even children are allowed to defecate in open [29].

Another study from India indicated that the conservative mindset and lack of awareness are barriers to transform sanitation-related knowledge into routine practice [26]. Our study reported that households with younger children have a high prevalence of all three childhood illnesses. Similarly, the unsafe child excreta disposal was higher in households with children aged 1-2 years. Infant or todlers have higher exposure to feces and dirt due to their frequent habit of putting objects, soil, and hands into their mouth [30].

Poor disposal of child feces is one of the harmful practices that directly contaminate water sources and poses a higher incidence of enteric infections for adults and young children [31]. The risks of unsafe faces disposal on child health have been studied for long, indicating the importance of safe management of child feces on child health [32]. We established that the risk of hazardous dumping of child feces was associated with diarrhea, cough, and fever among under-five children; the relationships were statisitcially significant. The result is in line with studies from several developing countries. For example, a study undertaken in Bangladesh suggested a strong connection between unimproved disposal of child feces and faltered child development [22].

Developing countries are practicing various sanitation interventions to improve the toilet facility at the household level, mainly assisting in places where open defecation is ubiquitous [33]. However, less attention was given to the disposal

Page $12 / 18$ 
and management of child feces, which is critical in reducing exposure to fecal pathogens [34]. A hospital-based empirical investigation conducted in Myanmar found that hospital admission due to rotavirus diarrhea has doubled than in the 1980s. Nearly $10 \%$ of hospitalization of under-fives was due to rotavirus diarrhea; the virus was found to be more prevalent in children aged between six and sevententh months [35].

Research findings of this paper indicates a positive association between inadequate toilet facility and experiencing cough and fever among under-five children. A supporting multicountry WASH-intervention based study showed that improved sanitation facilities decreased the risks of fever by $13 \%$ and of cough by $10 \%$; however, the reduction in childhood mortality was very low [36]. This study suggests the absence of all three WASH facilities being associated with cough, fever, and diarrhea. Similar research conducted in Nigeria reported higher odds of suffering from cough, fever, and diarrhea among households without all three types of WASH facilities [37].

This paper found a positive relationship between child poor nutritional status (stunting) and childhood illnesses. For example, the incidence of dirrhea was found higher among stunted children. The stunted children were associated with households having access to inadequate drinking water, and unsafe child feces disposal. Contrary to this, a study from Bangladesh concluded that the WASH intervention showed no effect on childhood illnesses and nutrition status between treatment and control communities. It could be due to the smaller number of observations and a shorter period between baseline and end-line intervention [21].

However, some researches have suggested that WASH interventions do not affect child nutritional status $[19,28]$. Recently a study used cluster-randomized trial in rural Zimbabwe to evaluate the implications of WASH related interventions on chronic child malnutrition. The results showed no direct association between WASH-related interventions and stunting; however, it revealed significant reduction in diarrhea in rural areas where stunting was substantially higher [20]. A recent multi-country study showed an improved child nutritional status if improved child feces disposal is practiced in developing countries [30]. Another study conducted in Peru assessed the implications of WASH on the nutrition levels of children using anthropometry measurement. Authors established a positive association between improved WASH and decreased incidence in diarrhea, and improved linear growth in children [38]. Amongst countries in the Association of Southeast Asian Nations, Myanmar has one of the largest numbers of stunted and underweight children aged 0-59 months.

The nutritional outcomes in children are directly associatd with WASH and diarrhea incidence. Repeated occurrence of diarrhea in the first 24 months of life increases the likelihood of being stunted and consequently preventing children from optimal physical and cognitive development [39]. Another case-control study showed that children registered with WASH and nutrition intervention have a lower risk of getting severely stunted and underweight after two years compared to nonregistered ones [19].

This paper has few limitations. It used a cross-sectional data set that can undermine the causality of WASH-related factors and childhood illnesses. Besides the WASH-related factors, several socio-demographic characteristics such as place of residence and WASH intervention factors in the study could act as confounding or reverse causal factors, which may inflate the prevalence of childhood illnesses. MDHS collects data on childhood illnesses based on the mother's recall, which is liable to recall biases and could be different from the clinical assessment of the child suffering from any ailment.

\section{Conclusion}

To sum up, this study confirms the association of common childhood illnesses with the inaccessibility of improved WASH facilities, especially among the rural and the poor. It implies that unimproved WASH is contributing to a higher burden of childhood illnesses in the Maynmar. Like many similar studies, the findings of the present study support that 
WASH is a fundamental component of public healthcare. The study calls for strengthening the multipronged strategies in partnership with local community and internatonal health care providers to ensure safeguarding WASH and achieve SDG 3 (target, 3.3) and SDG 6 (targets, $6.1 ; 6.2 ; 6 . A ; 6 . B$ ). Health education program targeting poor, illiterate, and rural is needed to create awareness on treating drinking water, hygienic practices, and safe disposal of child feces.

\section{List Of Abbreviations}

AOR; Adjusted Odds Ratio, CAFÉ; computer-assisted field editing, Cl; Confidence Interval, LMICs; low- and middle-income countries, MDHS; Myanmar Demographic and Health Survey, JMP; Joint Monitoring Program, NGOs; non-governmental orgainzations, PCA; Principle Component Analysis, PPS; probability proportional size, PSUs; primary sampling units, SDGs; Sustainable Development Goals, UNICEF; United Nations Children's Fund, USAID; United States Agency for International Development, WASH; Water, Sanitation and Hygiene, WHO; World Health Organization

\section{Declarations}

\section{Ethics approval and consent to participant}

Ethical Review Committee of the Myanmar Ministry of Health and Sports, Department of Medical Research granted ethical approval to ICF international and DHS program to coordinate with the ministry of sports and Health and conduct the first Myanmar Demographic and Health Survey during 2015-16. Authors have been granted the permission from ICF and USAID to use the MDHS 2015-16 for the current research.

\section{Consent for publication}

Authors have agreed to submit this research to BMC Public Health.

\section{Availability of data and materials}

We acknowledge to the DHS program-USAID for providing access to download the Myanmar Demographic and Health Survey 2015-16 from its website to conduct this research. The following is the link of Myanmar Demographic and Health survey 2015-16 used in this manuscript. The data is publically available and can be downloaded with the due permission at the following link, https://dhsprogram.com/data/dataset/Myanmar_Standard-DHS_2016.cfm?flag=0.

\section{Competing Interest}

The authors declare that they have no known competing interests.

\section{Funding}

This study has not received any financial support from any organization.

\section{Authors' Contributions}

LN and UG have conceived the concept, and outlined research questions and methodology. LN analyzed the data and carried out analytical and empirical assessment of research questions. UG has written the background, results and discussion, and conclusion LN has written Material and Methods, LN has thoroughly revised the manuscript. LN and UG have critically evaluated the paper. LN and UG have agreed on the final version of the manuscript.

\section{Acknowledgements}

We would like to acknowledge Measure DHS for granting access to datasets for this study. 


\section{References}

1. World Health Organization. Progress on household drinking water, sanitation and hygiene 2000-2017. Special focus on inequalities. New York: United Nations Children's Fund (UNICEF) and World Health Organization; 2019. https://www.unicef.org/media/55276/file/Progress on drinking water, sanitation and hygiene 2019.pdf.

2. Troeger C, Colombara DV, Rao PC, Khalil IA, Brown A, Brewer TG, et al. Global disability-adjusted life-year estimates of long-term health burden and undernutrition attributable to diarrhoeal diseases in children younger than 5 years. Lancet Glob Heal. 2018;6:e255-69.

3. Gakidou E, Afshin A, Abajobir AA, Abate KH, Abbafati C, Abbas KM, et al. Global, regional, and national comparative risk assessment of 84 behavioural, environmental and occupational, and metabolic risks or clusters of risks, 19902016: a systematic analysis for the Global Burden of Disease Study 2016. The Lancet. 2017;390:1345-422.

4. Alemayehu B, Ayele BT, Kloos H, Ambelu A. Individual and community-level risk factors in under-five children diarrhea among agro-ecological zones in southwestern Ethiopia. Int J Hyg Environ Health. 2020;224:1-8.

5. World Health Organization. Water and Sanitation for Health Facility Improvement Tool (WASH FIT): a practical guide for improving quality of care through water, sanitation and hygiene in health care facilities. Geneva: World Health Organization; 2017. https://apps.who.int/iris/bitstream/handle/10665/254910/9789241511698-eng.pdf.

6. Prüss-Ustün A, Wolf J, Bartram J, Clasen T, Cumming O, Freeman MC, et al. Burden of disease from inadequate water, sanitation and hygiene for selected adverse health outcomes: An updated analysis with a focus on low-and middle-income countries. Int J Hyg Environ Health. 2019;222:765-77.

7. Pruss-Ustun A. and WHO. Safer water, better health. 2008;2020 22 April. http://www.who.int/quantifying_ehimpacts/publications/saferwater/en/.

8. Bartram J, Cairncross S. Hygiene, sanitation, and water: forgotten foundations of health. PLoS Med. 2010;7:11. https://journals.plos.org/plosmedicine/article/file?id=10.1371/journal.pmed.1000367\&type=printable.

9. Desa UN. Transforming our world: The 2030 agenda for sustainable development. United Nations; 2016. https://stgwedocs.unep.org/bitstream/handle/20.500.11822/11125/unep_swio_sm1_inf7_sdg.pdf?sequence=1.

10. World Health Organization. UN-water global analysis and assessment of sanitation and drinking-water (GLAAS) 2014 report: investing in water and sanitation: increasing access, reducing inequalities. Geneva: World Health Organization; 2014. https://apps.who.int/iris/bitstream/handle/10665/139735/9789241508087_eng.pdf? sequence $=1$.

11. United Nations Development Program. Myanmar Annual Report for 2018. Myanmar: United Nations Development Programme; 2019. https://www.undp.org/content/dam/myanmar/docs/Publications/PovRedu/undp-mm-annualreport-2018-eng.pdf.

12. Zaw PPT, Htoo TS, Pham NM, Eggleston K. Disparities in health and health care in Myanmar. The Lancet. 2015;386:2053.

13. Ministry of Immigration and Population Health. The 2014 Myanmar Population and Housing Census: The Union Report. Washington, D.C.: Department of Population; 2015. https://unstats.un.org/unsd/demographicsocial/census/documents/Myanmar/MMR-2015-05.pdf.

14. Asian Development Bank. Urban Development and Water Sector Assessment, Strategy, and Road Map. Manila: Asian Development Bank; 2013. https://themimu.info/sites/themimu.info/files/documents/Report_Urban_Water_Sector_Assessment_ADB_2013.pdf.

15. Ministry of Health, department of public health child health division. Study on Cause of Under-five Mortality. Myanmar: Nay Pyi Taw, Myanmar: Ministry of Health and Sports, Myanmar.; 2014. https://www.unicef.org/myanmar/media/3941/file/Study in Cause of Under-five Mortality.pdf. 
16. United Naions. Resolution 64/292 (A/RES/64/292) adopted by the General Assembly on 28 July 2010. Geneva: United Nations; 2010. https://www.un.org/waterforlifedecade/human_right_to_water.shtml.

17. Grace K, Frederick L, Brown ME, Boukerrou L, Lloyd B. Investigating important interactions between water and food security for child health in Burkina Faso. Popul Environ. 2017;39:26-46.

18. Anderson BA, Romani JH, Phillips HE, Van Zyl JA. Environment, access to health care, and other factors affecting infant and child survival among the African and coloured populations of South Africa, 1989-94. Popul Environ. 2002;4:349-64.

19. Luby SP, Rahman M, Arnold BF, Unicomb L, Ashraf S, Winch PJ, et al. Effects of water quality, sanitation, handwashing, and nutritional interventions on diarrhoea and child growth in rural Bangladesh: a cluster randomised controlled trial. Lancet Glob Heal. 2018;6:e302-15.

20. Humphrey JH, Mbuya MNN, Ntozini R, Moulton LH, Stoltzfus RJ, Tavengwa NV, et al. Independent and combined effects of improved water, sanitation, and hygiene, and improved complementary feeding, on child stunting and anaemia in rural Zimbabwe: a cluster-randomised trial. Lancet Glob Heal. 2019;7:e132-47.

21. Huda TMN, Unicomb L, Johnston RB, Halder AK, Sharker MAY, Luby SP. Interim evaluation of a large scale sanitation, hygiene and water improvement programme on childhood diarrhea and respiratory disease in rural Bangladesh. Soc Sci Med. 2012;75:604-11.

22. George CM, Oldja L, Biswas S, Perin J, Sack RB, Ahmed S, et al. Unsafe child feces disposal is associated with environmental enteropathy and impaired growth. J Pediatr. 2016;176:43-9.

23. Ministry of Health and Sports. ICF. Myanmar Demographic and Health Survey 2015-16. Nay Pyi Taw, Myanmar, and Rockville, Maryland USA: Ministry of Health and Sports and ICF. 2017. https://dhsprogram.com/pubs/pdf/FR324/FR324.pdf.

24. World Health Organization, United Nations Children's Emergency Fund. Progress on drinking water and sanitation: 2014 update. Geneva: World Health Organization and UNICEF; 2017. https://apps.who.int/iris/bitstream/handle/10665/112727/9789241507240_eng.pdf?sequence=1.

25. World Health Organization. Water and Sanitation for Health Facility Improvement Tool (WASH FIT): a practical guide for improving quality of care through water, sanitation and hygiene in health care facilities. Geneva: World Health Organization; 2017.

26. Barrett R, Randle J. Hand hygiene practices: nursing students' perceptions. J Clin Nurs. 2008;17:1851-7.

27. Bessenecker C. A study of child-related excreta disposal practices and beliefs in a peri-urban community of Ciudad Juarez, Mexico. University of Texas Health Science Center at Houston, School of Public Health; 1994.

28. Clasen T, Boisson S, Routray P, Torondel B, Bell M, Cumming O, et al. Effectiveness of a rural sanitation programme on diarrhoea, soil-transmitted helminth infection, and child malnutrition in Odisha, India: a cluster-randomised trial. Lancet Glob Heal. 2014;2:e645-53.

29. Yeager BA, Huttly SR, Bartolini R, Rojas M, Lanata CF. Defecation practices of young children in a Peruvian shanty town. Soc Sci Med. 1999;49:531-41.

30. Bauza V, Byrne DM, Trimmer JT, Lardizabal A, Atiim P, Asigbee MAK, et al. Child soil ingestion in rural Ghanafrequency, caregiver perceptions, relationship with household floor material and associations with child diarrhoea. Trop Med Int Heal. 2018;23:558-69.

31. Walker CLF, Perin J, Aryee MJ, Boschi-Pinto C, Black RE. Diarrhea incidence in low-and middle-income countries in 1990 and 2010: a systematic review. BMC Public Health. 2012;12:220.

32. Lanata CF, Huttly SRASRA, Yeager BAC. Diarrhea: whose feces matter? Reflections from studies in a Peruvian shanty town. Pediatr Infect Dis J. 1998;17:7-9. doi:10.1097/00006454-199801000-00003.

33. Mara D, Lane J, Scott B, Trouba D. Sanitation and health. PLoS Med. 2010;7. 
34. Garn JV, Sclar GD, Freeman MC, Penakalapati G, Alexander KT, Brooks P, et al. The impact of sanitation interventions on latrine coverage and latrine use: A systematic review and meta-analysis. Int J Hyg Environ Health. 2017;220:32940.

35. Moe K, Hummelman EG, Oo WM, Lwin T, Htwe TT. Hospital-Based Surveillance for Rotavirus Diarrhea in Children in Yangon, Myanmar. J Infect Dis. 2005;192 Supplement_1:111-3. doi:10.1086/431509.

36. Gera T, Shah D, Sachdev HS. Impact of Water, Sanitation and Hygiene Interventions on Growth, Non-diarrheal Morbidity and Mortality in Children Residing in Low- and Middle-income Countries: A Systematic Review. Indian Pediatr. 2018;55:381-93.

37. He Z, Bishwajit G, Zou D, Yaya S, Cheng Z, Zhou Y. Burden of Common Childhood Diseases in Relation to Improved Water, Sanitation, and Hygiene (WASH) among Nigerian Children. Int J Env Res Public Heal. 2018;15.

38. Checkley W, Gilman RH, Black RE, Epstein LD, Cabrera L, Sterling CR, et al. Effect of water and sanitation on childhood health in a poor Peruvian peri-urban community. The Lancet. 2004;363:112-8.

39. World Health Organization

Malnutrition fact sheet

World Health Organization. Malnutrition fact sheet. 2017; 10 April. https://www.who.int/en/news-room/factsheets/detail/malnutrition.

\section{Figures}

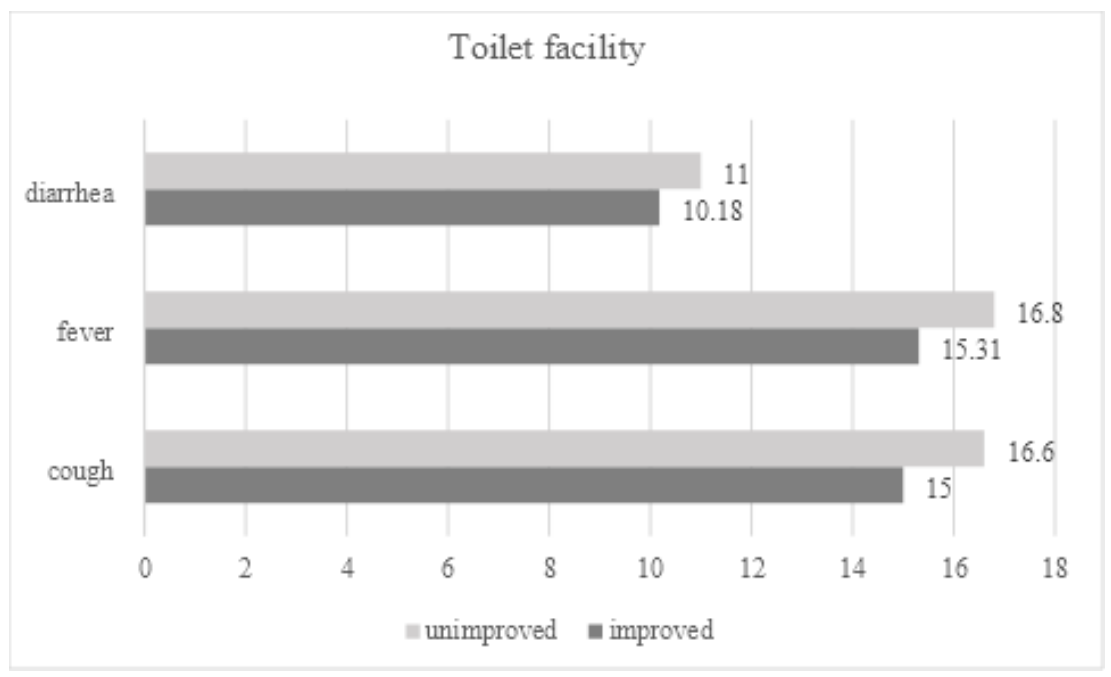

\section{Figure 1}

The prevalence of cough, fever, diarrhea by toilet facility 


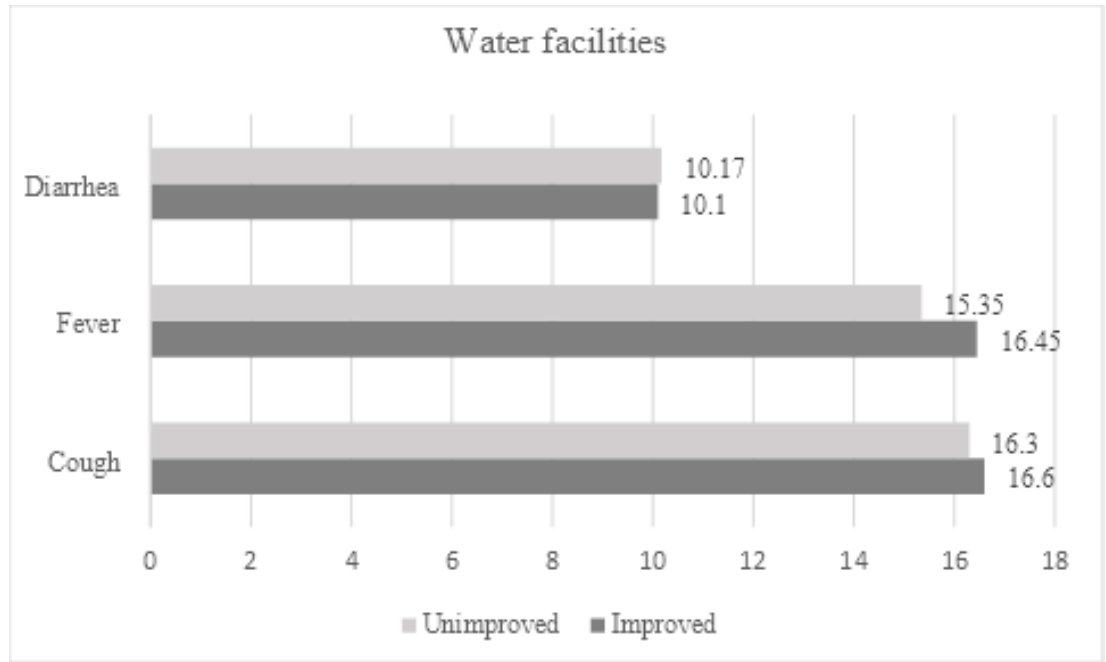

\section{Figure 2}

The prevalence of cough, fever and diarrhea by water facilities

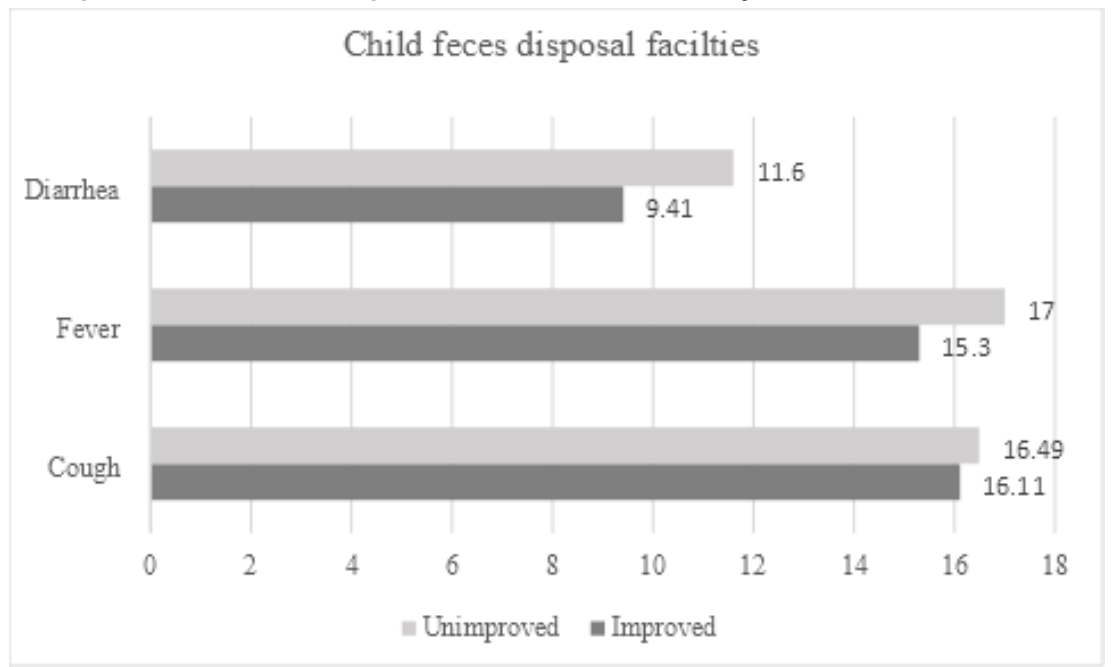

Figure 3

The prevalence of cough, fever, and diarrhea by child feces disposal facilities 